\title{
RELAP5 Calculations of Bethsy 9.1b Test
}

\author{
Andrej Prošek \\ Reactor Engineering Division, Jožef Stefan Institute, Jamova Cesta 39, 1000 Ljubljana, Slovenia \\ Correspondence should be addressed to Andrej Prošek, andrej.prosek@ijs.si
}

Received 21 April 2011; Accepted 14 September 2011

Academic Editor: Klaus Umminger

Copyright (C) 2012 Andrej Prošek. This is an open access article distributed under the Creative Commons Attribution License, which permits unrestricted use, distribution, and reproduction in any medium, provided the original work is properly cited.

Recently, several advanced computational tools for simulating reactor system behavior during real and hypothetical transient scenarios were developed. The TRAC/RELAP Advanced Computational Engine (TRACE) is the latest in a series of advanced, best-estimate reactor system codes developed by the United States Nuclear Regulatory Commission (US NRC). Nevertheless, the RELAP5/MOD3.3 computer code will be maintained in the next years. The purpose of the present study was to assess how the accuracy of Bethsy 9.1b test calculation depends on the US NRC RELAP5 code version used. Bethsy 9.1b test (International Standard Problem no. 27) was $5.08 \mathrm{~cm}$ equivalent diameter cold leg break without high-pressure safety injection and with delayed ultimate procedure. Seven different RELAP5 code versions were used and as much as possible the same input model. The obtained results indicate that the results obtained by the oldest and latest RELAP5 versions are in general comparable for Bethsy $9.1 \mathrm{~b}$ test. This is very important for the validity of the results, obtained in the past with older RELAP5 versions. Due to the fact that observation was restricted to Bethsy 9.1 b posttest, with its own physical phenomena, this conclusion could be generalized only for scenarios having similar range of the considered Bethsy transient conditions.

\section{Introduction}

Recently, several advanced computational tools for simulating reactor system behavior during real and hypothetical transient scenarios were developed. In the past, the United States Nuclear Regulatory Commission (US NRC) RELAP5 computer code was one of the most used in the international community. Since the release of RELAP5/MOD2 in 1985 the code was continuously improved and extended. Several new models, improvements to existing models, and user conveniences have been added to the latest RELAP5/MOD3.3 Patch 04 release in 2010 [1].

In the past, the Jožef Stefan Institute (JSI) activities in the area of RELAP5 analyses have been aimed also to extend the experiences in simulations of small break loss of coolant accidents (LOCAs) and two-phase natural circulation cooling. Therefore, its own RELAP5 input model of Bethsy facility [2] has been developed. The Bethsy-experiences-based improved modeling methods have been used in simulations of real plant transients and evaluation of plant accident management procedures [3-5]. In 1996 the BETHSY 9.1b test has been analyzed with three different versions of RELAP5 code (MOD2, MOD3.1, and MOD3.1.2 without any modification of the codes and with guidelines consideration) using experimental data [4]. The aim of this study was to perform calculations with to JSI available RELAP5 versions using as much as possible the same input model in order to see the differences between the code versions. Namely, in the past, typical comparisons were done between new and old versions, while this comparison covers the last 25 years of US NRC RELAP5 development.

\section{Methodology Description}

First the Bethsy experimental facility is described. Then the Bethsy $9.1 \mathrm{~b}$ test is described. Then the RELAP5 code versions used are listed, followed by description of RELAP5 input model development. Finally, the calculations are described.

2.1. Description of Bethsy Integral Test Facility. Bethsy is an integral test facility, which was designed to simulate most pressurized water reactor accidents of interest, to study accident management procedures and to validate the computer codes. It is a scaled down model of three-loop Framatome (now AREVA NC) nuclear power plant with the thermal power $2775 \mathrm{MW}$ (see Figure 1). Volume, mass flow, and power 


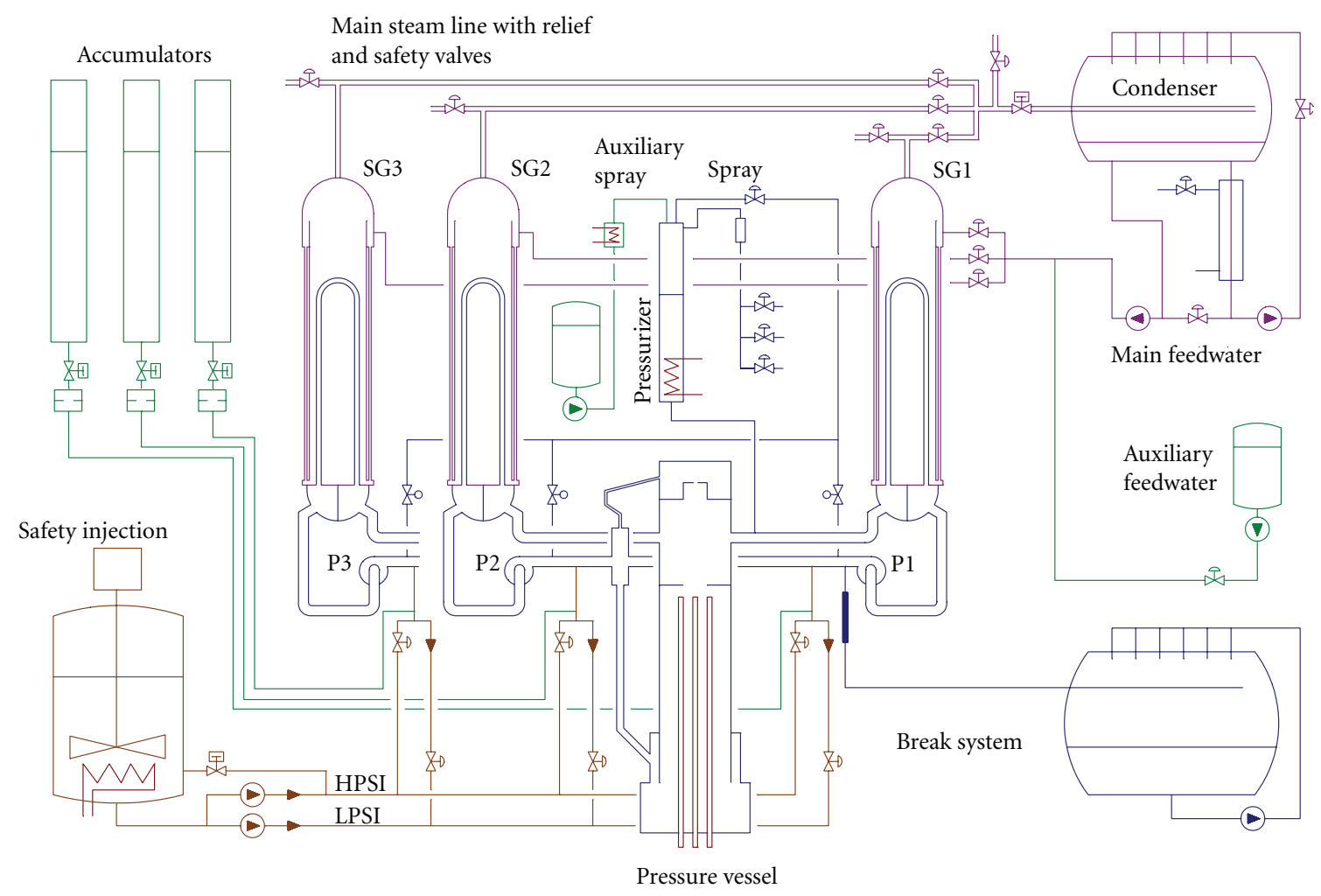

Figure 1: Bethsy facility.

are scaled to $1: 96.9$, while the elevations and the pressures of the primary and secondary systems are preserved [2]. The design pressure on the primary side is $17.2 \mathrm{MPa}$ and on the secondary side $8 \mathrm{MPa}$. The power is limited to the decay heat level, therefore the transient without reactor trip cannot be simulated. The facility is equipped with all systems and measurement system needed for the performance and for observing the analyzed transients. The facility consists of pressure vessel, reactor coolant pumps and piping, heat tracing system, the system for break simulation, instrumentation, and the control systems. The core is cylindrical and is composed of 428 electrically heated rods and of 29 guide thimbles. The rods are arranged to the $17 \times 17$ core square lattice. The core power is $3 \mathrm{MW}$, which is $10 \%$ of the reference power considering scaling. The break system enables simulation of the break in different locations, that is, in cold leg, lower plenum, pressurizer, steam generator $U$ tubes, and feedwater pipe. The instrumentation data system measures all data needed for the transient analysis. The control system can simulate the plant control systems and operator actions.

\subsection{Description of $9.1 \mathrm{~b}$ Test Performed in BETHSY Facility.} The Bethsy 9.1.b test is a scaled $5.08 \mathrm{~cm}$ cold leg no. 1 break without high-pressure safety injection and with delayed operator action for secondary system depressurization. Due to core heatup the operator depressurized the secondary side by atmospheric relief steam dump valves. In the simulation this operator action was delayed. The test was analyzed in the frame of international standard problem 27 (ISP 27) performed to validate the thermal hydraulic computer codes.
The test scenario was the following: break was opened in the cold leg no. 1 (initiation of the transient). When the maximum heater rod cladding temperature reache $723 \mathrm{~K}$, the ultimate procedure is started by opening three steam line dumps to atmosphere. When pressurizer pressure dropped below 4.2 $\mathrm{MPa}$, accumulators started to inject and they stopped to inject below 1.46 MPa. The low-pressure safety injection system was activated when the primary pressure was below $0.91 \mathrm{MPa}$. When stable residual heat removal system operating conditions prevailed, the transient was terminated.

\subsection{Description of RELAP5 Computer Code. The US NRC} RELAP5 computer code is one of the most widely spread system thermal hydraulic codes in the world. In spite of the fact that US NRC priority is TRACE [6], RELAP5 computer code is still maintained. In spite of its wide use, the RELAP5 is one-dimensional code and its importance will fall with time, especially when TRACE will be fully developed.

The basic RELAP5 thermal-hydraulic model uses six equations: two mass conservation equations, two momentum conservation equations, and two energy conservation equations. Closure of the field equations is provided through the use of constitutive relations and correlations. Since the release of RELAP5/MOD2 in 1985 the code was continuously improved and extended. Several new models, improvements to existing models, and user conveniences have been added to the latest RELAP5/MOD3.3 Patch 04 release in 2010. In Table 1 RELAP5 versions which were used in this study are listed. 
TABLE 1: The RELAP5 code versions used.

\begin{tabular}{lccc}
\hline Name & Version & Release date & Label \\
\hline RELAP5/MOD2 & 36.05 & March 1987 & MOD2 \\
RELAP5/MOD3 & $5 \mathrm{M} 5$ & March 1990 & MOD3 \\
RELAP5/MOD3.1 & & March 1993 & MOD3.1 \\
RELAP5/MOD3.2.2 Beta & $3.2 \mathrm{jb}$ & July 1998 & MOD3.2 \\
RELAP5/MOD3.3 & $3.3 \mathrm{bf}$ & February 2002 & MOD3.3 \\
RELAP5/MOD3.3 Patch03 & $3.3 \mathrm{gl}$ & March 2006 & MOD3.3P3 \\
RELAP5/MOD3.3 Patch04 & $3.3 \mathrm{iy}$ & October 2010 & MOD3.3P4 \\
\hline
\end{tabular}

2.4. RELAP5 Input Model Description. The RELAP5/MOD2 input model was developed, when participating to ISP-27. It was initialized according to the specified data for each test. Each of the three coolant loops was represented explicitly without taking into account the small asymmetry between the loops. The base RELAP5/MOD2 model of Bethsy facility for pretest calculations contained 196 volumes, 207 junctions, and 191 heat structures [7]. This base RELAP5/MOD2 input model was further upgraded to RELAP5/MOD3.1 and RELAP5/MOD3.1.2, which is shown in Figure 2 [7]. The base RELAP5/MOD2 input model was renodalized, increasing the number of nodes in reactor coolant system piping (from 9 to 45 nodes), reactor coolant pumps (2 nodes more not shown in Figure 2), core bypass sections (from 1 to 12 nodes), reactor vessels (two more in the head), and downcomers (from 5 to 14 nodes). The elevations of parallel volumes of the reactor downcomer, in bypass, reactor core, hot leg, and cold leg were preserved. Nodalization of the reactor core, pressurizer, reactor head, upper plenum, and lower plenum remained the same. This RELAP5 input model of Bethsy facility, called middle input model, is shown in Figure 2 and contains 332 volumes, 343 junctions, and 330 heat structures. This RELAP5 model was further refined, increasing the number of nodes in the steam generator. The U-tubes were modeled with 20 nodes instead of 10, and the downcomer and riser regions of steam generator were modeled with 11 nodes instead of five, which gives 22 more nodes per steam generator and 66 more nodes in total. The large RELAP5 input model of Bethsy facility thus contains 398 volumes, 408 junctions, and 396 heat structures. The nodalization study [4] showed that in general for most parameters and control variables there are no essential differences between the results of the more detailed and less detailed nodalizations. It was also found that a more detailed nodalization may lead to more accurate prediction of void fraction but it also may lead to less accurate prediction of other variables, for example, maximal cladding temperature. The developed RELAP5 input models [7] were extensively used to extend the experiences in simulations of small break loss of coolant accidents and two-phase natural circulation cooling. The Bethsy-experiencesbased improved modeling methods were used in the simulations of real plant transients and evaluation of plant accident management procedures.

Later, the middle input model was used for Bethsy 6.2TC [8] calculations by RELAP5/MOD3.2, with some slight nodalization changes. The junction from the guide tube to the upper plenum was removed based on previous experience and downcomer-upper head bypass volume has been subdivided into 3 volumes. Such model consisted of 335 volumes, 344 junctions, and 333 heat structures.

The detailed input model developed for Bethsy $9.1 \mathrm{~b}$ test was used also for Bethsy 6.9c test calculations [9], with some minor modifications. There were some geometrical differences between both tests, and some elements from the detailed input model for Bethsy 9.1b test were excluded. Some new elements were introduced. A broad check on the consistency of the geometrical changes has been made by rerunning test 9.1, using the new modified model for test 6.9c. In the input model the following elements and systems are included: 377 volumes, 381 junctions, and 404 heat structures.

In 2000, a common RELAP5/MOD3.2 input model was developed based on the model developed for Bethsy $6.9 \mathrm{c}$ test, which evolved from the large input model. The common input model for all available Bethsy tests consisted of 398 volumes, 408 junctions, and 402 heat structures [10] (see Table 2). This input model is very similar to the large input model, with the exception that the vessel upper head was modeled with more nodes and only one auxiliary feedwater system was modeled in steady-state contributing to less nodes (in case of Bethsy $9.1 \mathrm{~b}$ test two systems need to be defined, one before and one after ultimate procedure). The needed components were then added during restart calculation. This input model was adapted for the use of RELAP5/ MOD3.3, with no changes in the geometry and the number of hydrodynamic components and heat structures. The hydrodynamic view was generated by SNAP from RELAP5 input model (in ASCII) and then arranged manually using Model Editor of SNAP (see Figure 3). The RELAP5/MOD3.3 input model in terms of SNAP consists of 141 hydrodynamic components and 72 heat structures. The difference is that pipes consist of several volumes; however they are considered as one component. Similar is the case with the heat structures.

2.5. Description of RELAP5 Calculations. Most of the calculations listed in Table 3 were performed in 2011. However, as middle input deck should be restored from the report [4] and RELAP5/MOD3 was not running on the SUN, for three calculations the archived results were used. The calculations presented in [4] were performed on SUN SPARCstation 20 


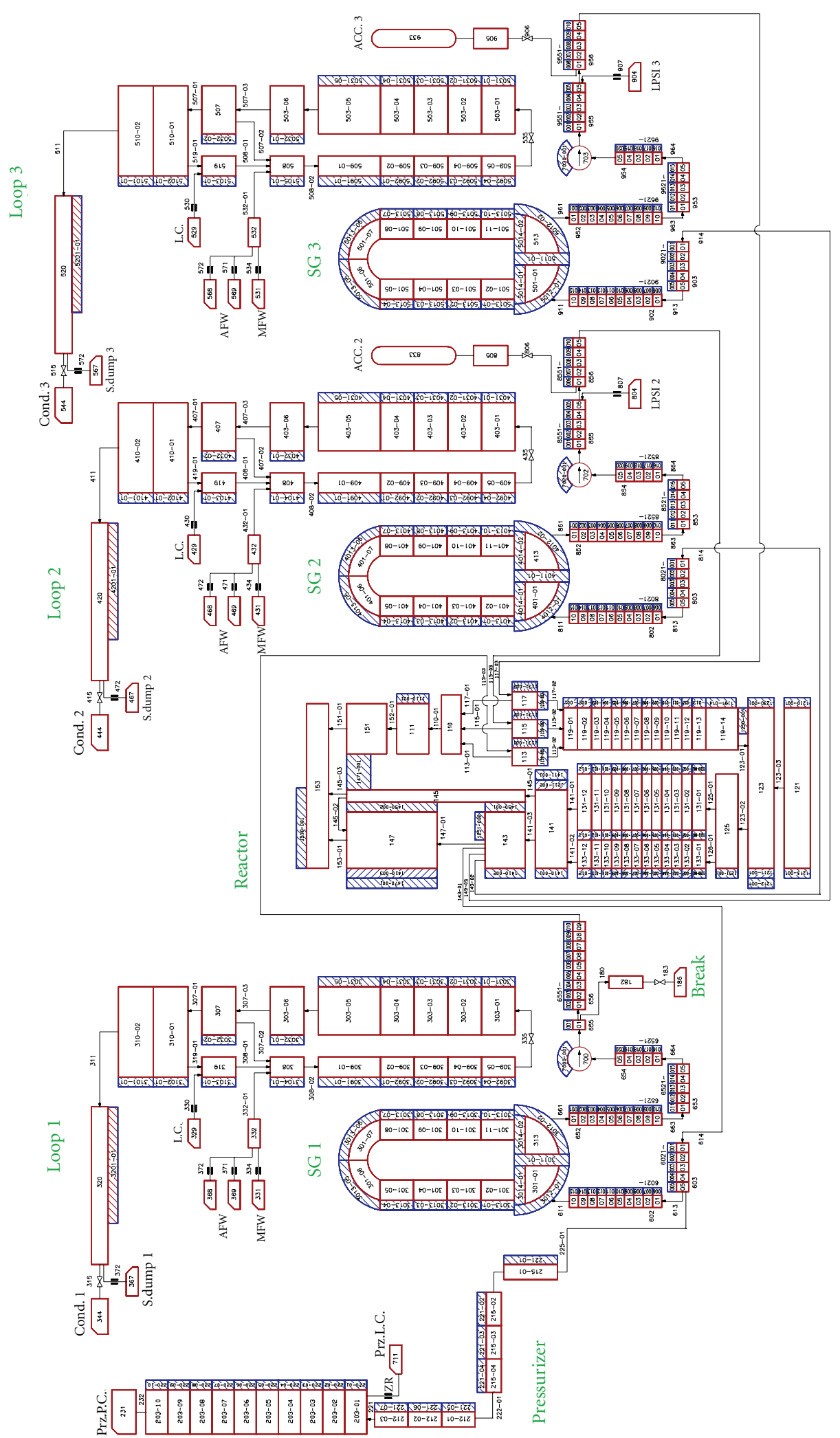

Figure 2: RELAP5/MOD3.1 input model of Bethsy facility. 


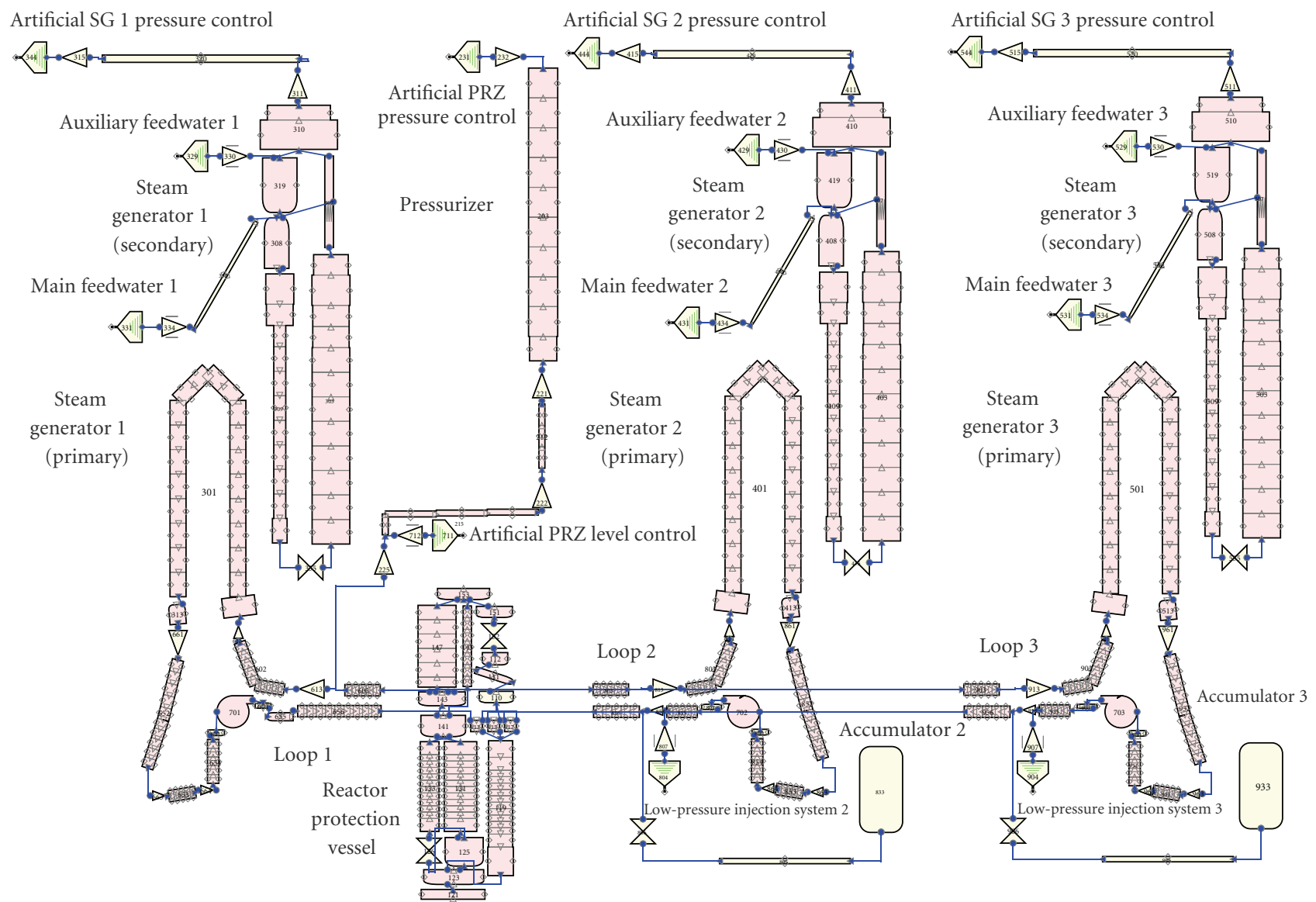

FIGURE 3: SNAP hydrodynamic component view of RELAP5/MOD3.3 input model of Bethsy facility.

TABLE 2: RELAP5 input models used.

\begin{tabular}{lcccc}
\hline Name & Label & Volumes & Junctions & Heat structures/mesh points \\
\hline Small input model & $(\mathrm{S})$ & 198 & 207 & $191 / 754$ \\
Middle input model & $(\mathrm{M})$ & 332 & 343 & $330 / 1290$ \\
Large input model & $(\mathrm{L})$ & 398 & 408 & $396 / 1554$ \\
Common input model & $(\mathrm{C})$ & 398 & 408 & $401 / 1573$ \\
\hline
\end{tabular}

TABLE 3: RELAP5 calculations performed.

\begin{tabular}{|c|c|c|c|c|c|c|}
\hline Analyzed Case & Code used & Input model used & Discharge coefficient & Machine & Operating system & Year \\
\hline MOD2 (S) & RELAP5/MOD2 & Small & $0.85,1.2$ & SUN & SOLARIS 9 & 2011 \\
\hline MOD3 (M) & RELAP5/MOD3 & Middle & $0.85,1.2$ & SUN & SOLARIS 2.5 & 1998 \\
\hline MOD3.1 (M) & RELAP5/MOD3.1 & Middle & $0.8,1.0,1.1$ & SUN & SOLARIS 2.5 & 1998 \\
\hline MOD3.1 (C) & RELAP5/MOD3.1 & Common & $0.8,1.0,1.1$ & SUN & SOLARIS 9 & 2011 \\
\hline MOD3.2 (L) & RELAP5/MOD3.2 & Large & N.A. & SUN & SOLARIS 8 & 2001 \\
\hline MOD3.2 (C) & RELAP5/MOD3.2 & Common & $0.8,1.0,1.1$ & SUN & SOLARIS 9 & 2011 \\
\hline MOD3.3 (C) & RELAP5/MOD3.3 & Common & $0.8,1.0,1.1$ & SUN & SOLARIS 9 & 2011 \\
\hline MOD3.3 P3 (C) & $\begin{array}{l}\text { RELAP5/MOD3.3 } \\
\text { Patch } 03\end{array}$ & Common & $0.8,1.0,1.1$ & $\mathrm{PC}$ & Windows XP Sp3 & 2011 \\
\hline MOD3.3 P4 (C) & $\begin{array}{l}\text { RELAP5/MOD3.3 } \\
\text { Patch } 04\end{array}$ & Common & $0.8,1.0,1.1$ & $\mathrm{PC}$ & Windows XP Sp3 & 2011 \\
\hline
\end{tabular}


(4-processor workstation) which uses multiuser and multitasking operating system SOLARIS 2.5. The other calculations were performed on a SUN FIRE V880 server (with four UltraSPARC III 750-megahertz processors, with 16 gigabytes main RAM, running under the SOLARIS 9 operating system) except the RELAP5/MOD3.3 Patch 03 and Patch 04 running on PC. Finally, one calculation with large input model, very similar to common input model, was performed on a SUN Enterprise 450 workstation with a $4 \times 400$ megahertz central processing unit $(\mathrm{CPU})$ and $4 \times 2$ gigabytes of random-access memory, running under a SOLARIS 8 operating system. The information on computers and operating systems is given as the code versions were created on the specific computers and the executables could not be moved to other computers. Without still running old SUN machines the calculations could not be performed without building the new executables (for PC versions this would be quite demanding). The objective of this study was not to study dependence on computers and operating systems. The platform dependency study has been done in [11] for RELAP5/MOD3.3 Patch 04, showing very small differences for the LOFT L2-5 test and no differences for the LOFT L3-7 test.

Also, it should be noted that RELAP5/MOD2 was not able to run large input model due to not enough virtual space furnished for unit $=54$. Finally, as was previously mentioned, the study [7] concluded that more detailed nodalization can lead to more accurate prediction of void fraction which is very important for correct break discharge forecast. However, it also may lead to less accurate prediction of other variables as maximum cladding temperature in the case of MOD2 and MOD3.1.

\section{Results}

The results are shown in Figures 4, 5, 6, 7, 8, 9, 10, 11, 12, 13, and 14 for nine cases described in Table 3. For calculations not performed in 2011 some variables were missing in the archive. In such cases the calculation is labeled as N.A. Nevertheless, the majority of data was available. Also, as can be seen from Table 4, the cases with some missing variables have been performed at slightly different boundary conditions and nodalization details. According to [7] this influence is not so big; therefore the response could be assigned mostly to the code version. Also the discharge coefficients were as much as possible the same. In old RELAP5 versions two values of discharge coefficient were specified (subcooled and two phase), while in newer RELAP5 versions three values of discharge coefficient were specified (subcooled, two phase, and superheated).

3.1. Steady-State Calculation. The initial conditions for steady-state calculation are shown in Table 4. For the common input model the initial conditions are the same. Some very small differences are due to different code versions. Older the code version is, a bit larger they are. In the case of small, medium, and large input model the initial conditions were selected somewhat different compared to common model. However, they were within the measurement uncertainty. In

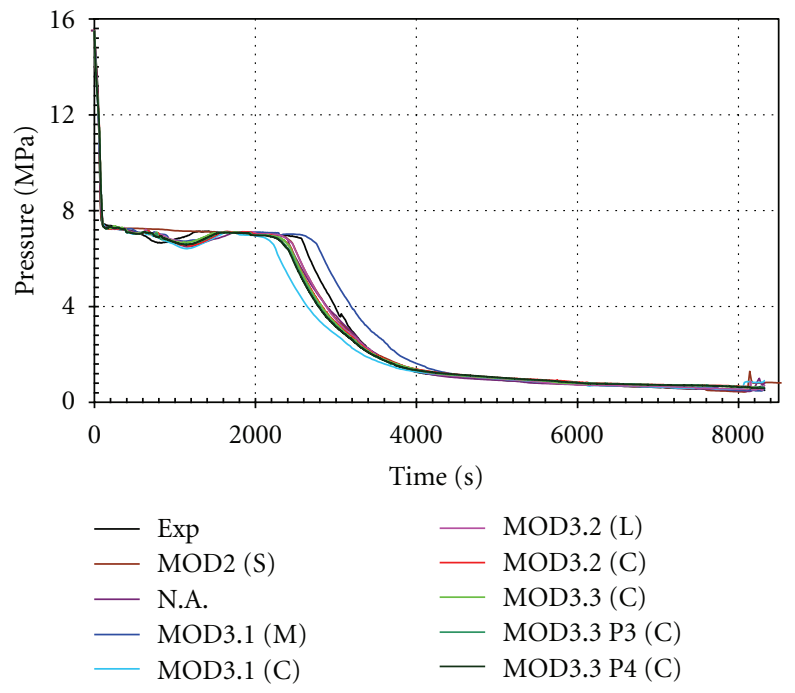

FIgURE 4: Pressurizer pressure.

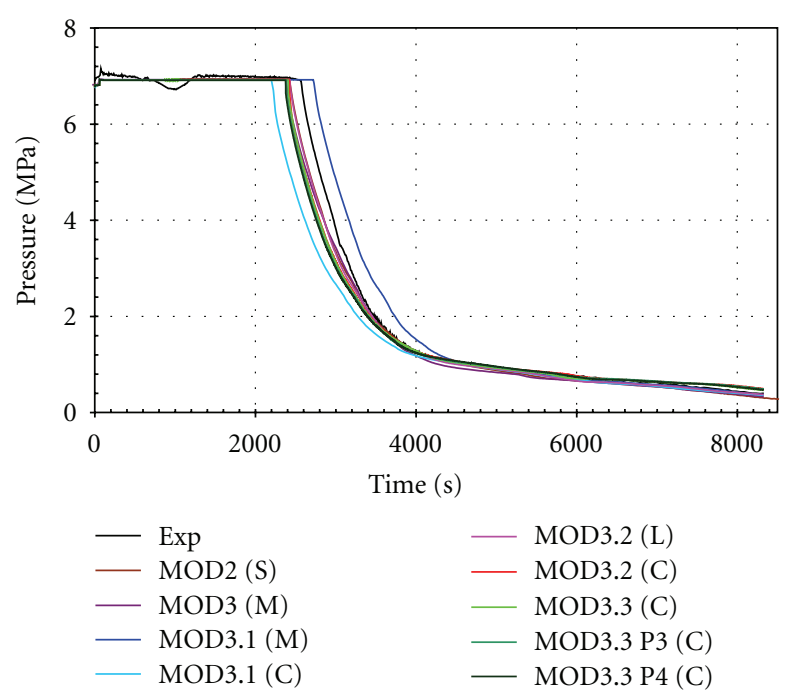

Figure 5: Secondary pressure.

general it can be said that the initial conditions were practically the same for all calculations.

3.2. Transient Calculation. Table 5 shows the sequence of the main events. The sequence of events is shown only for the calculations with the oldest and the latest RELAP5 version. The timing is similar for both code versions. After break opening the scram signal is generated, followed by safety injection (SI) signal. The main feedwater system is off and secondary pressure is kept constant until ultimate procedure initiation. The secondary inventory loss is recovered by auxiliary feedwater system operation. The primary pump is coasted down $300 \mathrm{~s}$ after SI signal. All these times are in quite close agreement with the experimental data. As high pressure injection is not available, the core starts to uncover and when maximum heater rod cladding temperature reaches $723 \mathrm{~K}$, the ultimate procedure was started by opening three steam 
TABLE 4: Initial conditions for Bethsy 9.1b test.

\begin{tabular}{|c|c|c|c|c|c|c|c|}
\hline Parameter & Measured & $\begin{array}{l}\text { MOD2 } \\
(\mathrm{S})\end{array}$ & $\begin{array}{l}\text { MOD3 } \\
(\mathrm{M})\end{array}$ & $\begin{array}{l}\text { MOD3.1 } \\
(\mathrm{M})\end{array}$ & $\begin{array}{l}\text { MOD3.1 } \\
\text { (C) }\end{array}$ & $\begin{array}{c}\text { MOD3.2 } \\
\text { (L) }\end{array}$ & $\begin{array}{c}\text { MOD3.2 (C), MOD3.3 } \\
\text { (C), MOD3.3 P3 (C), } \\
\text { MOD3.3 P4 (C) }\end{array}$ \\
\hline Core thermal power $(\mathrm{kW})$ & $2864 \pm 30$ & 2864 & 2864 & 2864 & 2864 & 2864 & 2864 \\
\hline Cold leg temperature (per loop) (K) & $559.9 \pm 0.5$ & 560.3 & 560.3 & 560.3 & 559.35 & 559.8 & 559.35 \\
\hline Downcomer mass flow rate $(\mathrm{kg} / \mathrm{s})$ & $150.0 \pm 5.0$ & 151 & 152.7 & 154.3 & $154.1^{\mathrm{a}}$ & 150.0 & 155.4 \\
\hline Reactor coolant pump speed (per loop) (rpm) & $2940 \pm 30$ & 2970 & 2970 & 2940 & 2970 & 2970 & 2970 \\
\hline Pressurizer pressure (MPa) & $15.51 \pm 0.09$ & 15.51 & 15.51 & 15.51 & 15.51 & 15.51 & 15.51 \\
\hline Pressurizer level (m) & $4.08 \pm 0.1$ & N.A. & N.A. & 4.12 & 4.08 & 4.08 & 4.08 \\
\hline Reactor coolant system mass (kg) & 1960 & 1948 & 1948 & 1948 & 1948 & 1949 & 1948 \\
\hline Secondary side pressure (per SG) (MPa) & $6.91 \pm 0.04$ & 6.83 & 6.81 & 6.81 & 6.74 & 6.81 & 6.76 \\
\hline Steam generator level (per SG) (m) & $13.45 \pm 0.05$ & 13.44 & N.A. & 13.45 & 13.20 & 13.14 & 13.25 \\
\hline Feedwater temperature $(\mathrm{K})$ & $491.1 \pm 2.0$ & 491.0 & 491.0 & 491.0 & 491.0 & 491.0 & 491.0 \\
\hline Secondary coolant mass (per SG) (kg) & $820 \pm 30$ & 800 & 819 & 821 & 790 & 790 & 790 \\
\hline RCS trace heating $(\mathrm{kW})$ & 107.5 & $107.5^{\mathrm{a}}$ & $107.5^{\mathrm{a}}$ & $107.5^{\mathrm{a}}$ & $107.5^{\mathrm{a}}$ & $107.5^{\mathrm{a}}$ & $107.5^{\mathrm{a}}$ \\
\hline
\end{tabular}

${ }^{a}$ No heat losses considering when the trace heating system is on; rather, heat losses are simulated after accumulator emptying.

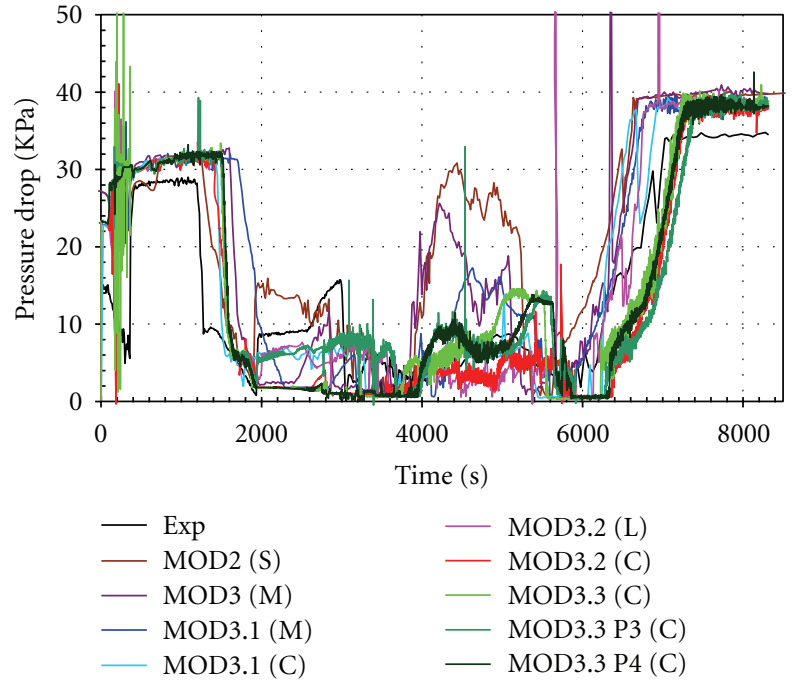

Figure 6: Cross-over leg 1 downflow side differential pressure.

line dumps to atmosphere, in the calculations a bit earlier than in the experiment. This causes secondary pressure decrease, followed by primary system pressure decrease. When primary system dropped below the accumulator injection setpoint, the injection started and soon the cladding temperature started to decrease. Again the heatup in the calculation is earlier than in the experiment. Later the accumulators are emptied; however, cooling is established through the secondary side, and therefore the primary pressure decreases. Reaching the low-pressure injection system setpoint, the lowpressure injection started and the experiment lasted until the stable residual heat removal system conditions were reached.

In Figures 4-14 calculated results are shown for the main variables. As it is difficult to compare so many calculations, line colors are selected in such a way that MOD3.3 versions have green color palette, MOD3.2 are in red and pink, and MOD3.1 has blue palette. Pressurizer pressure is shown in

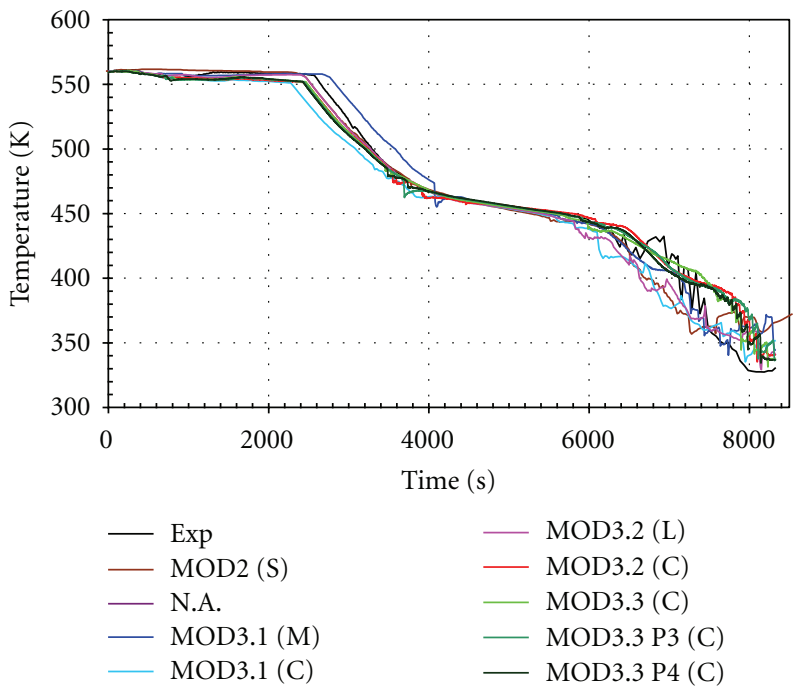

Figure 7: Core inlet temperature.

Figure 4. It may be seen that all calculated lines are like a bunch except lines for RELAP5/MOD3.1 version. In addition, RELAP5/MOD2 calculation has no pressure drop around $1000 \mathrm{~s}$ as the other code versions. Similar is the situation for secondary pressure shown in Figure 5. Again RELAP5/MOD3.1 calculations are outside the bunch of lines. Figure 6 for crossover leg no. 1 downflow side differential pressure shows that the code versions behave much differently. The core inlet and outlet temperature lines shown in Figures 7 and 8 also look like a bunch. In addition, some differences appear also after low-pressure injection. For core outlet temperature shown in Figure 8 the calculated values are fluid temperatures only, which explains the mismatch with experimental data during the core heatup period, measuring mixture temperature. Break flow is shown in Figure 9 and mass discharged at the break in Figure 10. Up to $340 \mathrm{~s}$ the RELAP5/MOD2 deviates from the bunch, later the largest 
TABLE 5: Sequence of main events for Bethsy $9.1 \mathrm{~b}$ test.

\begin{tabular}{|c|c|c|c|}
\hline \multirow{2}{*}{ Events } & \multicolumn{3}{|c|}{ Time (s) } \\
\hline & Exp & MOD3.3 P4 (C) & MOD2 (S) \\
\hline Break opening & 0 & 0 & 0 \\
\hline Scram signal (13.1 MPa) & 41 & 32 & 39 \\
\hline Safety injection signal (11.9 MPa) & 50 & 54 & 54 \\
\hline Main feedwater off, turbine bypass & 54 & 58 & 58 \\
\hline Core power decay start (17 s after scram) & 58 & 49 & 56 \\
\hline Auxiliary feedwater on (30 s after SI signal) & 82 & 84 & 84 \\
\hline Pump coastdown start ( $300 \mathrm{~s}$ after SI signal) & 356 & 354 & 354 \\
\hline End of pump coastdown & 971 & 969 & 969 \\
\hline Start of the first core level depletion & 1830 & 1841 & 1760 \\
\hline Start of second core uncover & 2180 & 2102 & 2060 \\
\hline Ultimate procedure initiation & 2562 & 2375 & 2410 \\
\hline Accumulator injection start (4.2 MPa) & 2962 & 2750 & 2840 \\
\hline Primary mass inventory is minimum & 2970 & 2750 & 2840 \\
\hline Maximum core cladding heatup & 3053 & 2910 & 2900 \\
\hline Accumulator isolation (1.5 MPa) & 3831 & 3809 & 3888 \\
\hline Low-pressure injection system start (0.91 MPa) & 5177 & 5627 & 5139 \\
\hline End of test/calculation & 8200 to 8330 & 8330 & 8900 \\
\hline
\end{tabular}

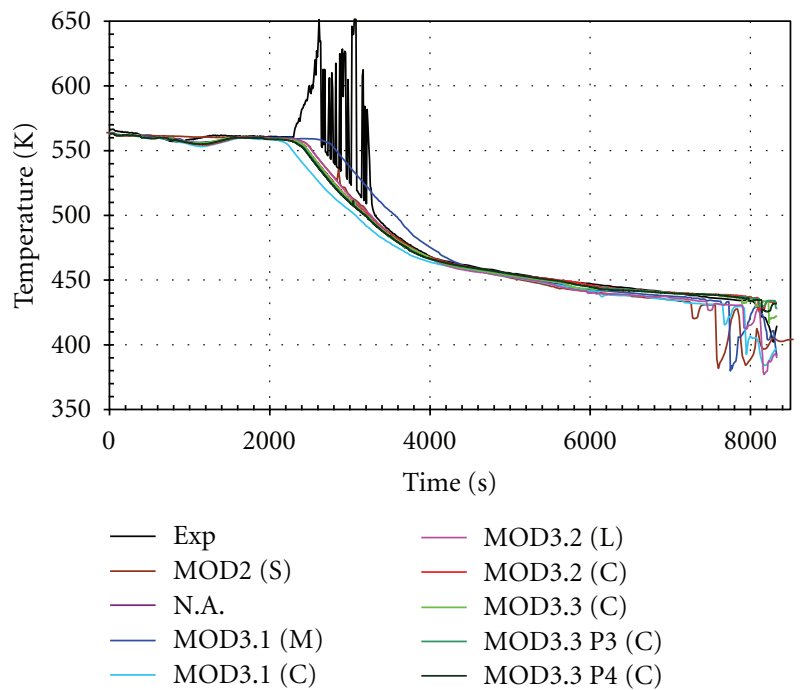

Figure 8: Core outlet temperature.

deviation is for RELAP5/MOD3.1, which causes earlier and later core heatup, as shown in Figure 11. The largest peak cladding temperature was obtained by RELAP5/MOD2 code, where the largest core uncovery was predicted as shown in Figure 12. Again only RELAP5/MOD3.1 calculations deviate from the bunch of lines. The time of low-pressure injection depends on the primary pressure prediction, showing a spectrum of delays, indicating that there are some differences between the code versions in spite of bunch behavior for most of the variables. Finally, Figure 14 shows the mass of the primary circuit. Mass is in the agreement with the mass discharged through the break and the mass injected with

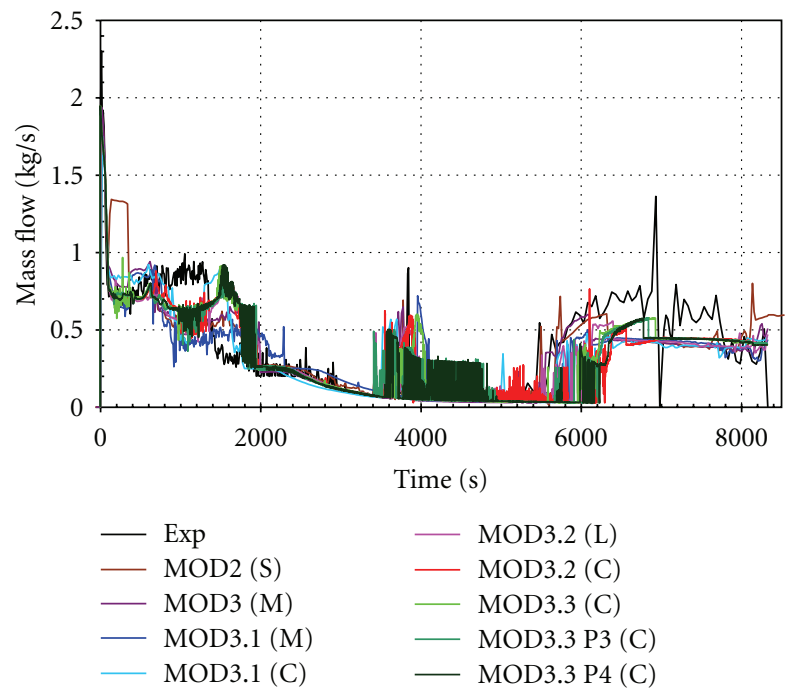

FIgURE 9: Break flow.

accumulators and low-pressure injection system. The differences are the largest at the end of transient, with the older RELAP5 version overpredicting and the newer versions underpredicting the mass.

3.3. Results Discussion. The results showed that qualitatively all RELAP5 versions in general produce similar results in spite of some differences in the boundary conditions and the nodalization details. Nevertheless, it may be very easily noted that RELAP5/MOD3.1 code is the only code version which more significantly deviates for some of the variables, mostly 

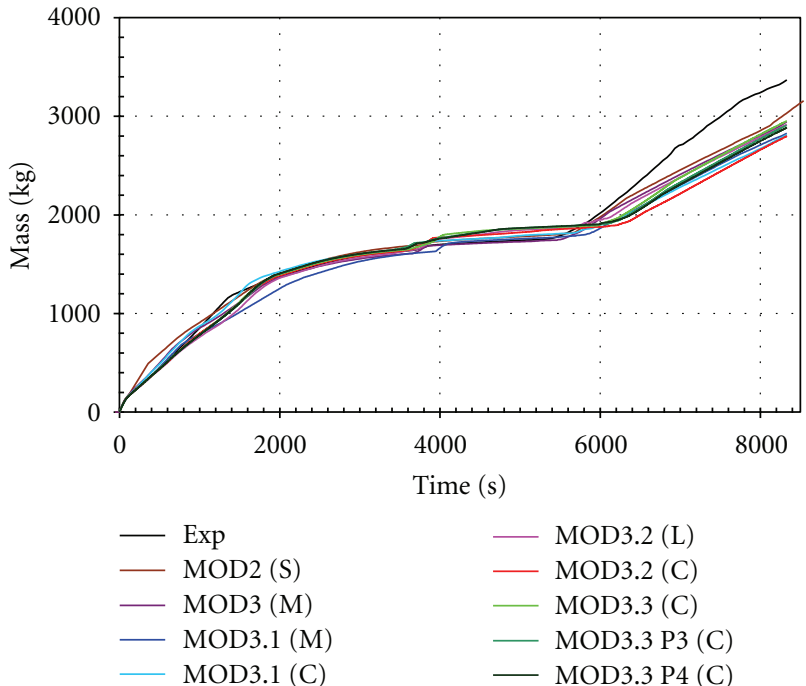

Figure 10: Mass discharged at the break.

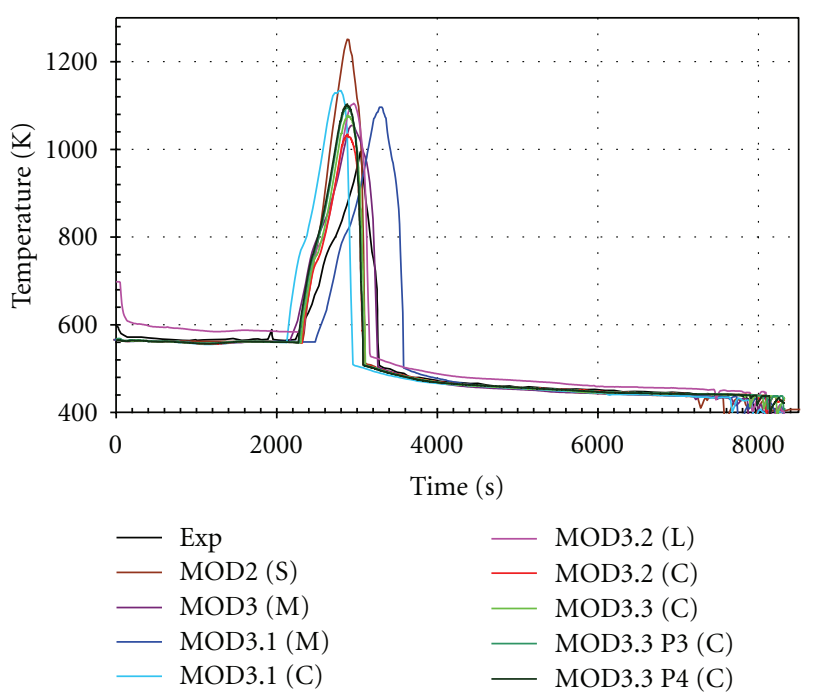

Figure 11: Maximum heater rod cladding temperature.

due to timing of heatup start, influencing the ultimate heat procedure initiation.

For peak cladding temperature the largest deviation from measured peak cladding temperature was obtained for RELAP5/MOD2 version. This may be due to small nodalization used. When referring to [7], it can be seen that large nodalization produces lower peak cladding temperatures. For RELAP5/MOD3.1 the difference is of the order $100 \mathrm{~K}$, while the difference between small and middle versions is of the order $50 \mathrm{~K}$. As RELAP5/MOD2 code version is limited by virtual memory for the code version we had, the calculation with common model was not possible. When looking the break flow one must be aware that RELAP5 old versions use only two discharge coefficients, while newer versions use three discharge coefficients. Nevertheless, based on Figures 9 and 10 significant differences were only for RELAP5/MOD2 calculation in the initial time interval from $100 \mathrm{~s}$ to $300 \mathrm{~s}$

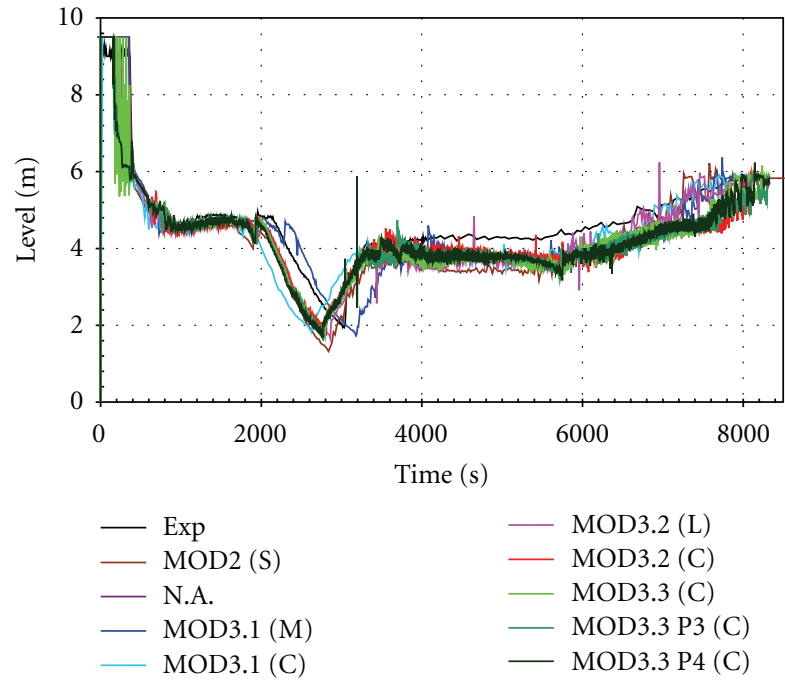

FIgURE 12: Core collapsed liquid level.

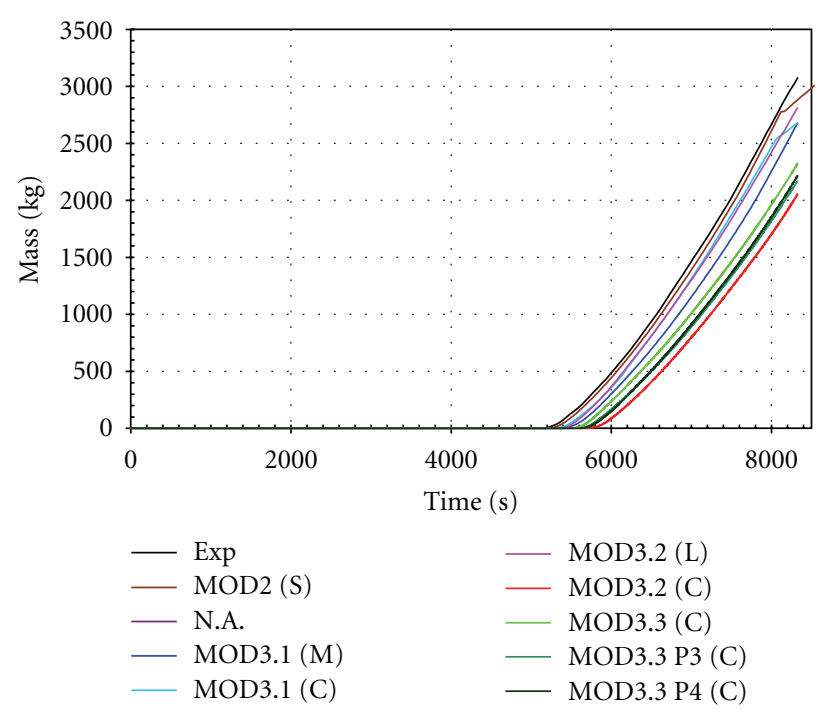

FIGURE 13: Injected mass by low-pressure system.

(overprediction) and RELAP5/MOD3 calculation in the time interval $1000 \mathrm{~s}$ to $3000 \mathrm{~s}$ (underprediction).

An important aspect was also second loop seal clearing due to condensation in the cold legs following the accumulator injections, which plays an important role upon the conditions of core temperature turnaround. When looking cross-over leg 1 downflow side differential pressure shown in Figure 6 it may be seen that the RELAP5 code versions do not predict the second loop seal clearing exactly in the same manner as seen in the test data. In the time interval from $2000 \mathrm{~s}$ to $4000 \mathrm{~s}$ the code versions are qualitatively different (even RELAP5/MOD3.3 Patch 03 and RELAP5/MOD3.3 Patch 04). When the accumulator stopped to inject, the older RELAP5 versions (MOD2 and MOD3) overpredicted differential pressure in the time interval $4000 \mathrm{~s}$ to $6000 \mathrm{~s}$.

In spite of the fact that significant development of the RELAP5 code was done, based on the obtained results one 


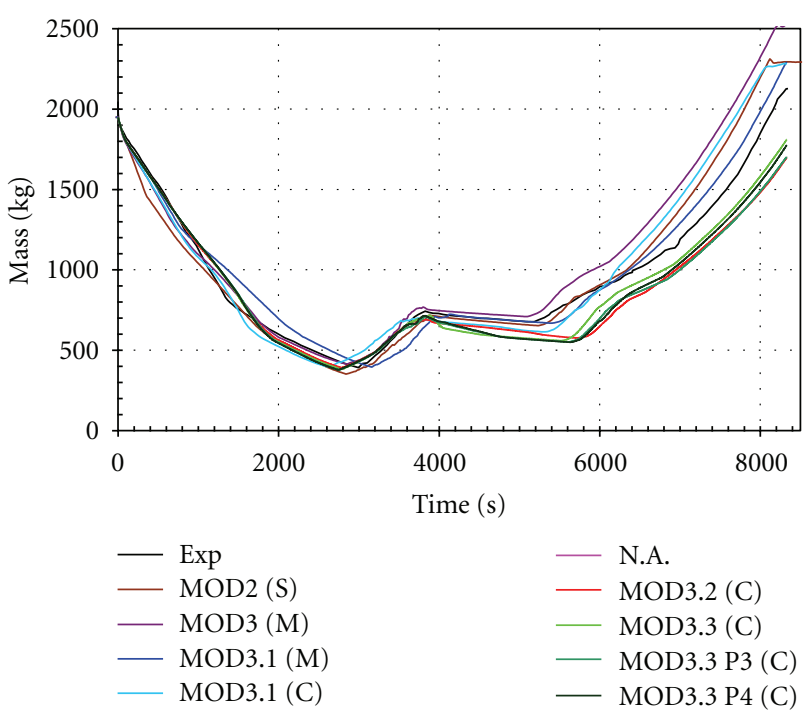

FIGURE 14: Primary system mass.

may conclude that the frozen RELAP5/MOD2 code can give comparable results to those of the latest RELAP5/MOD3.3 Patch 04 computer code. The agreement is good for the main variables describing the transient conditions such as pressures, temperatures, and system mass. On the other hand, for special phenomena of interest significant differences may appear, for example, break flow and condensation. It should be noted that the code accuracy was judged on the comparison of the trends. Due to the fact that the observation was restricted to the Bethsy 9.1b test, with its own physical phenomena, this conclusion could be generalized for scenarios having similar range of the considered Bethsy transient conditions. Nevertheless this does not mean that no development was made in the newer RELAP5 code versions or that development was not needed. Rather, the Bethsy $9.1 \mathrm{~b}$ test was performed at the time when the RELAP5/MOD2 was developed and the code version had the capabilities to simulate most important phenomena, which occurred during Bethsy 9.1 test. On the other hand, the JSI calculation was among the top ranked as judged by fast Fourier transform method for code accuracy quantification $[12,13]$ and further improvements are more difficult. These are one of the reasons why calculations performed later with newer versions were comparable, besides the fact that several developments were done to other phenomena not occurring or not important during such transient conditions, for example, the 3D phenomena and neutronics. Therefore it is not surprising that the RELAP5 results for the selected Bethsy $9.1 \mathrm{~b}$ test are almost as good as the results obtained by TRACE computer code using RELAP5 converted input model [14]. This is in agreement with the conclusion in [15] that maturity of thermal hydraulic codes was recognized also in the US NRC code consolidation program and further development was considered necessary only in specific areas, for example, multidimensional and multiphysics treatment of phenomena and transport of interfacial area. The development of thermal hydraulic codes was needed also because of special models for advanced reactors, for example, passive systems.

\section{Conclusions}

The Bethsy $9.1 \mathrm{~b}$ test, which is $5.08 \mathrm{~cm}$ equivalent diameter cold leg break without high-pressure safety injection and with delayed ultimate procedure, was simulated by different RELAP5 code versions using input models, originating from the same RELAP/MOD2 posttest input model developed at Jožef Stefan Institute. The results showed that the calculations obtained by different RELAP5 versions are in general comparable, with the exception that RELAP5/MOD3.1 shows some deviations in timing of the heatup initiation. The agreement is good for the main variables describing the transient conditions such as pressures, temperatures, and system mass. On the other hand, for special phenomena of interest significant differences may appear, for example, break flow and condensation. This is very important for the validity of the results, obtained in the past with older RELAP5 versions. Due to the fact that observation was restricted to Bethsy 9.1b posttest, with its own physical phenomena, this conclusion could be generalized for scenarios having similar range of the considered Bethsy transient conditions. Nevertheless, development of RELAP5 was needed in the past, for example, RELAP5/MOD2 has limitations on the number of hydrodynamic components (limited nodalization details), which may influence the results. Finally, this example confirmed that the RELAP5 code performs satisfactorily for what was intended, while development of new U.S. NRC TRACE code replacing U.S. NRC RELAP5 has been primarily needed to extend the code capabilities, for example, multidimensional and multiphysics treatment of phenomena and special models needed for advanced passive reactors. Of course, modernization of the codes to current computers and higher accuracy is also a constant goal of code developers.

\section{Acknowledgments}

The author acknowledges the financial support from the state budget by the Slovenian Research Agency Program no. P20026 and financial support from Slovenian Nuclear Safety Administration and Krško Nuclear Power Plant by Project no. POG-3473.

\section{References}

[1] USNRC, "RELAP5/MOD3.3 code manual," Patch 04, Vols. 1 to 8, Information Systems Laboratories, Inc., Rockville, Maryland, Idaho Falls, Idaho, prepared for USNRC, 2010.

[2] CEA, "BETHSY, General Description,” Note SETh/LES/90-97, CEA (Commissariat à l'énergie atomique et aux énergies alternatives), Grenoble, France, April 1990.

[3] S. Petelin, B. Mavko, I. Ravnikar, and Y. A. Hassan, "Data transfer from BETHSY 9.1b experiment to real NPP," in Proceedings of the ASME International Mechanical Engineering Congress and Exposition, vol. 21, pp. 71-80, American Society of Mechanical Engineers, New York, NY, USA, November 1997.

[4] S. Petelin, B. Mavko, I. Ravnikar, P. Cebull, and Y. A. Hassan, "Nodalization study for BETHSY experiment," in Proceedings of the 4th ASME/JSME International Conference on Nuclear 
Engineering, vol. 1, pp. 955-962, New Orleans, La, USA, March 1996.

[5] S. Petelin, B. Mavko, B. Končar, and Y. A. Hassan, "Scaling of the small-scale thermal-hydraulic transient to the real nuclear power plant," Nuclear Technology, vol. 158, no. 1, pp. 56-68, 2007.

[6] U. S. Nuclear Regulatory Commission, TRACE V5.0 User Manual, Division of Risk Assessment and Special Projects, Office of Nuclear Regulatory Research, Washington, DC, USA.

[7] S. Petelin, B. Mavko, O. Gortnar, I. Ravnikar, and G. Černe, "Result of BETHSY test 9.1.b using RELAP5/MOD3," (NUREG/IA, 0141), U.S. Nuclear Regulatory Commission, Washington, DC, USA.

[8] S. Petelin and B. Končar, "RELAP5/MOD3.2 assessment on the BETHSY 6.2TC SBLOCA test," in Proceedings of the 4th Regional Meeting, Nuclear Energy in Central Europe, Bled, Slovenia, September 1997.

[9] S. Petelin, B. Mavko, and M. Jurkovič, "BETHSY-loss of the residual heat removal system during mid-loop operation," in Proceedings of the 5th International Conference on Nuclear Engineerin, pp. 1-10, The American Society of Mechanical Engineers, New York, NY, USA, May 1997.

[10] S. Hrvatin, A. Prošek, and I. Kljenak, "Quantitative assessment of the BETHSY 6.2 TC test simulation," in Proceedings of the 8th International Conference on Nuclear Engineering, The American Society of Mechanical Engineers, New York, NY, USA, 2000.

[11] RELAP5/MOD3.3 Patch04 PLATFORM DEPENDENCY, Information Systems Laboratories, Inc. Rockville, Maryland and Idaho Falls, Idaho, USA, 2010.

[12] F. D'Auria, M. Leonardi, and R. Pochard, "Methodology for the evaluation of thermalhydraulic codes accuracy," in Proceedings of the International Conference on New Trends in Nuclear System Thermohydraulics, Pisa, Italy, May-June 1994.

[13] A. Prošek, "Code accuracy evaluation of BETHSY experiments using FFTBM and SARBM," in Proceedings of the Annual Meeting on Nuclear Technology, Stuttgart, Germany, May 2002.

[14] A. Prošek and O.-A. Berar, "Analysis of small-break loss-ofcoolant accident test $9.1 \mathrm{~b}$ at BETHSY facility with TRACE and RELAP5," in Proceedings of the International Congress on Advances in Nuclear Power Plants (ICAPP '11), Nice, France, May 2011, Paper 11160.

[15] "OECD/NEA," in Proceedings of the Workshop Advanced Thermal-Hydraulic and Neutronic Codes: Current and Future Applications, Barcelona, Spain, April 2000, Report NEA/CSNI/ $\mathrm{R}(2001) 2 /$ VOL1. 

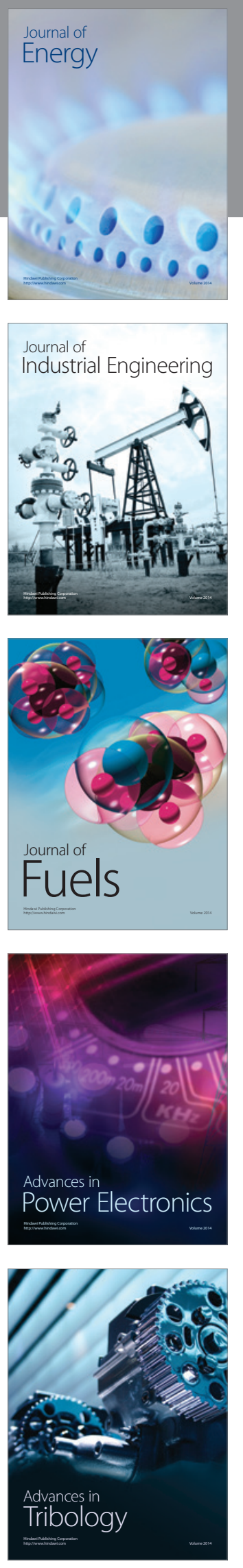
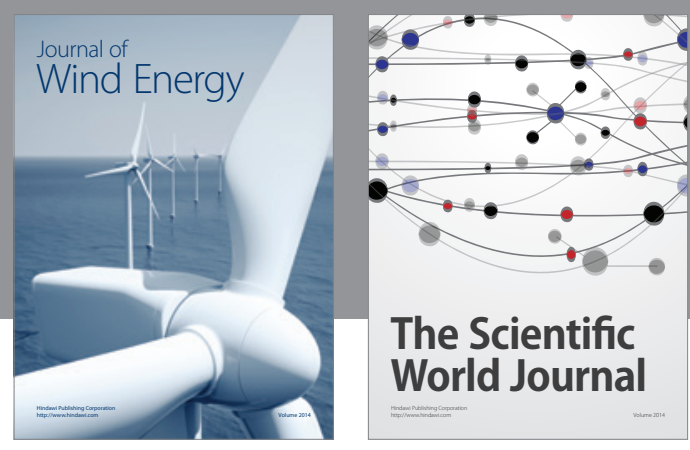

The Scientific World Journal

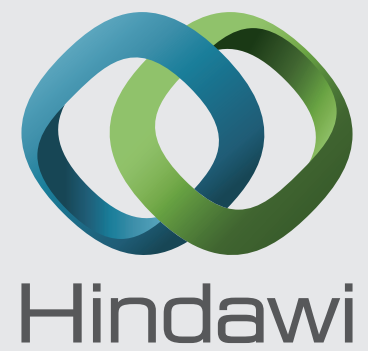

Submit your manuscripts at http://www.hindawi.com
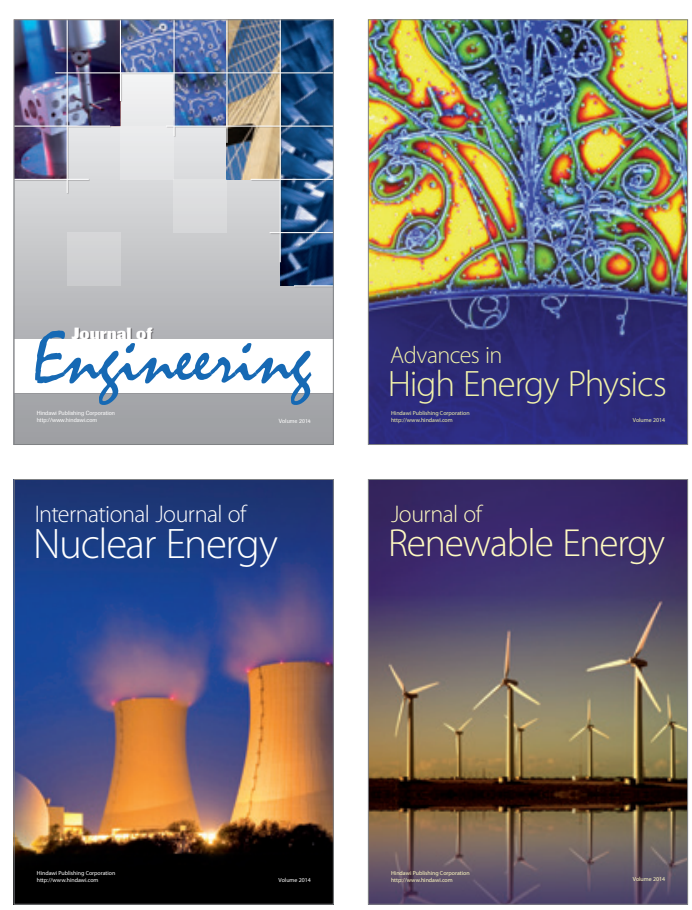

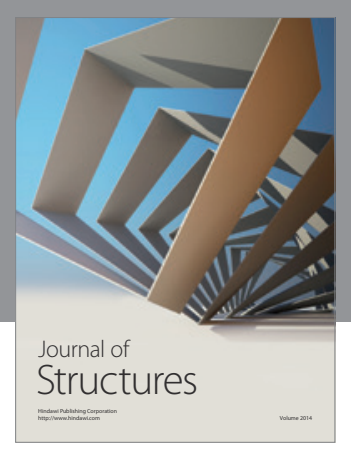

Rotating
Mechinery
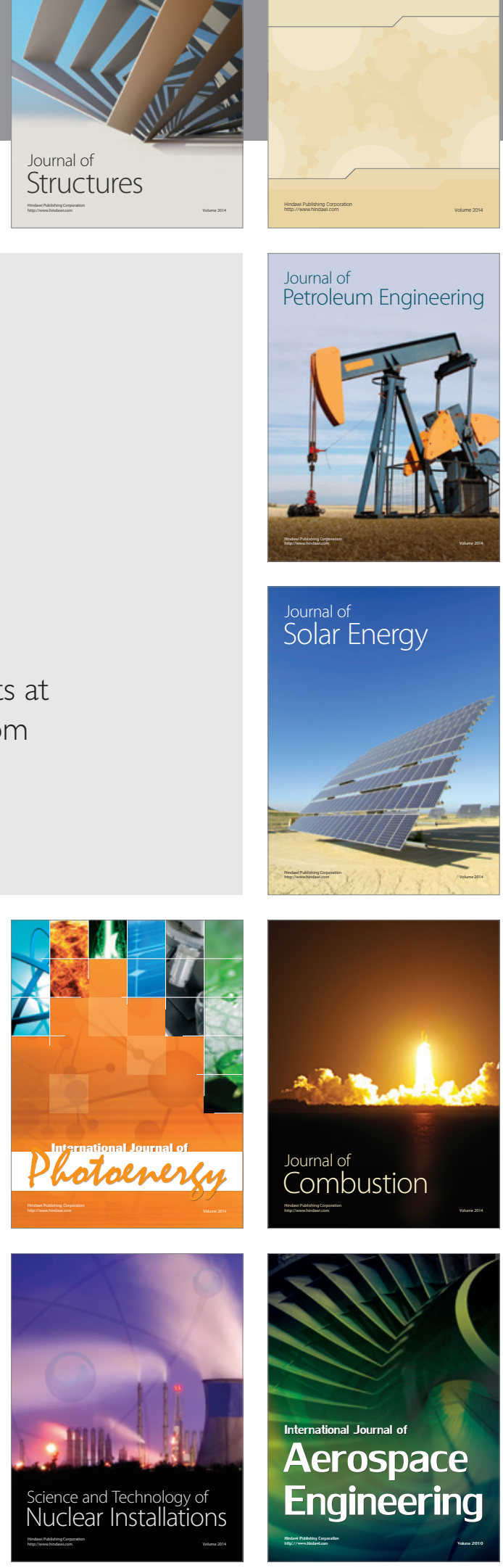